\begin{tabular}{l|l} 
REVISTA & $\begin{array}{l}\text { Revista Educación } \\
\text { ISSN: 0379-7082 } \\
\text { ISSN: 2215-2644 } \\
\text { revedu@gmail.com } \\
\text { Universidad de Costa Rica } \\
\text { Costa Rica }\end{array}$
\end{tabular}

\title{
Presentación: 45 Aniversario de la Revista Educación
}

Garbanzo Vargas, Guiselle M.

Presentación: 45 Aniversario de la Revista Educación

Revista Educación, vol. 45, núm. 1, 2021

Universidad de Costa Rica, Costa Rica

Disponible en: http://www.redalyc.org/articulo.oa?id=44064134040

DOI: https://doi.org/10.15517/revedu.v45i1.45237

\section{(c) $(1) \Theta \Theta$}

Esta obra está bajo una Licencia Creative Commons Atribución-NoComercial-SinDerivar 3.0 Internacional. 


\section{Presentación: 45 Aniversario de la Revista Educación}

Guiselle M. Garbanzo Vargas

Universidad de Costa Rica, Costa Rica

guiselle.garbanzo@ucr.ac.cr
DOI: https://doi.org/10.15517/revedu.v45i1.45237

Redalyc: http://www.redalyc.org/articulo.oa?id=44064134040

\section{Presentación: 45 Aniversario de la Revista Educación}

Hace cuarenta y cinco años, en 1976, avanzaba Costa Rica de la mano de la Universidad de Costa Rica, construyendo una nación, un país con grandes necesidades según los desafíos de su propia época. A pesar de las grandes carencias que como país se experimentaban, la esperanza, como siempre, estaba en el sistema educativo: se impulsaban cambios significativos en sus distintos espacios, pero principalmente desde la Facultad de Educación de la Universidad de Costa Rica.

En este contexto, surge en 1976 la Revista Educación de la Universidad de Costa Rica, que fue publicada por primera vez en 1977. Así, en esta oportunidad, y en calidad de Decana de la Facultad de Educación de la Universidad de Costa Rica y Directora de la Revista Educación de esta misma universidad, me complace compartir con la comunidad científica, a la cual va dirigida la Revista Educación, el Volumen 45, N. 1. La revista ha sabido caminar a lo largo de 45 años al servicio de sociedad en la difusión del conocimiento científico; ha superado los obstáculos que la historia le ha presentado.

Han sido cuarenta y cinco años de producir conocimiento mediante el trabajo de gran cantidad de académicos y académicas de distintas naciones, que han encontrado en Revista Educación un espacio científico para compartir los avances en materia educativa, insumos que por más de cuatro décadas han servido de forma sólida para la toma de decisiones en distintos espacios socioeducativos.

No es cualquier revista científica la que se ha sabido mantener por casi cinco décadas, sino que Revista Educación ha tenido que adaptarse a las necesidades emergentes; transitar de modelos tradicionales de difusión y alcances, a las exigencias que la modernidad le ha impuesto; ha tenido que reinventar la calidad de sus procesos de gestión y, sobre todo, su experiencia y carácter científico, que le ha permitido elevar sus niveles de calidad y que la ha colocado hoy en indexaciones de alto nivel en la comunidad científica, como Redalyc, Scielo, UCRIndex, Actualidad Iberoamericana, Latindex, (Emerging Sources Citation Index (ESCI), Web of Science (Master Journal List), ERIH PLUS (European Reference Index for the Humanities and the Social Sciences) y Academic Search Premier.

Además, se encuentra en las siguientes bases de datos: Latindex (Catálogo, Directorio y Revistas en linea), Directory of Open Access Journals (DOAJ), Web of Science (WOS) Clarivate Analytics, Clase (Citas Latinoamericanas en Ciencias Sociales y Humanidades), Dialnet, SHERPA / ROMEO, Iresie (Indice de Revistas de Educación Superior e Investigación Educativa), MIAR (Matriz de información para la evaluación de revistas), REDIB: Red Iberoamericana de Innovación y Conocimiento Cientifico, INFOBASE, REBIUM: Red de Bibliotecas Universitarias, COPAC, BASE (Bielefeld Academic Search Engine), GALE ACADEMIC ONEFILE, PAIS (Public Affairs Information Service), Fuente Academica Plus, EBSCO Education Source, MLA - Modern Language Association Database, Sociological abstracts.

Asimismo, se ubica en los catálogos: SUDOC (Catálogo del Sistema Universitario de Documentación Francés) y OCLC World Cat (Catálogo bibliográfico mundial). Igualmente, se encuentra en los siguientes directorios: Ulrich's (Global Serials Directory), Journals for free, OEI (Organización de Estados Iberoamericanos), Directorio Cultural de Sicultura, Ministerio de Cultura y Juventud, Red Latinoamericana 
de Revistas Académicas en Ciencias Sociales y Humanidades (LatinREV de FLACSO). También aparece en los buscadores: Google Scholar y Google Analytics.

Estoy segura de que la Revista Educación seguirá cosechando muchos logros académicos y seguirá al servicio de la sociedad con sus aportes de conocimiento a los sistemas educativos, los cuales requieren de este espacio de difusión. También sabrá superar sus diferentes momentos de crisis, que como toda revista los ha tenido, pero eso sí, ha sabido salir de ellos de forma exitosa, lo que le ha permitido posicionarse cada día como aquel espacio sólido, buscado por destacados académicos y académicas para compartir sus conocimientos.

Mi gratitud a todas las personas directoras y editoras, que a lo largo de la historia han estado a cargo de la esta Revista, así como a todo el equipo de profesionales y personal de apoyo, que han hecho posible que hoy la Facultad de Educación pueda honradamente presentar el Volumen 45, N. 1 de nuestra distinguida Revisa Educación, la cual cuenta con altos parámetros de calidad.

¿Que sean estas las sendas por las que siga avanzado la Revista Educación, siempre mejorando su calidad y procesos, pero, sobre todo, siendo un referente científico en el campo de la educación!

¡Mi eterna gratitud! 